\title{
Diferentes pré-inóculos, temperaturas e tempos de incubação na produção aflatoxina $B_{1}$ em arroz
}

\author{
Different previus inoculum, temperature and incubation time in the production of aflatoxin \\ $B_{1}$ in rice
}

\author{
Ana Carolina Ritter ${ }^{\mathrm{I}^{*}}$ Isa Beatriz Noll ${ }^{\mathrm{I}}$
}

\section{RESUMO}

Estudos indicam que um dos problemas mais sérios que afetam os manejos pré e pós-colheita do arroz é a presença de fungos das espécies Aspergillus ou Penicillium, potencialmente produtores de micotoxinas. Os objetivos deste trabalho foram avaliar a capacidade produtora de aflatoxina $B_{1}$ de cepas isoladas do arroz e observar o efeito do pré-inóculo nas mesmas. Foram utilizados três isolados de Aspergillus flavus, conhecidamente já produtores, que foram testados nas temperaturas de 20 e $25^{\circ} \mathrm{C}$, combinadas com tempos de incubação 11, 14 e 21 dias. Os pré-inóculos utilizados foram Yeast Extrat Sucrose (YES) e Czapeck Yeast Extrat (CYA). Todas as cepas retiradas do pré-inóculo em meio YES e inoculadas no arroz, em temperatura de $25^{\circ} \mathrm{C} / 18$ dias e $20^{\circ} \mathrm{C} / 14$ dias, produziram aflatoxina $B_{1} O$ meio $C Y A$ apresentou menor desempenho, uma vez que as três cepas testadas não produziram aflatoxina $B_{1}$ na combinação $20^{\circ} \mathrm{C} / 14$ dias. A $25^{\circ} \mathrm{C} / 11$ dias de incubação a aflatoxina $B_{1}$ não foi detectada.

Palavras-chave: Aspergillus flavus, CYA, YES, tempo de incubação, temperatura, arroz.

\section{ABSTRACT}

The production of aflatoxin in rice by three isolates of Aspergillus flavus was investigated for different culture conditions (temperature and incubation time) and previous inoculum (YES- Yeast Extrat Sucrose and CYA- Czapeck Yeast Extrat). All strains withdrawn from the previous inoculum medium YES and inoculated in the rice in temperature of $25^{\circ} \mathrm{C} /$ 18 days and $20^{\circ} \mathrm{C} / 14$ days, produced aflatoxin $B_{1}$. The medium CYA had lower performance since the three strains tested did not produce aflatoxin $B_{1}$ in the combination $20^{\circ} \mathrm{C} / 14$ days. At $25^{\circ} \mathrm{C} / 11$ days of incubation time aflatoxin was not detectable.

Key words: Aspergillus flavus, CYA, YES, incubation time, temperature, rice.

\section{INTRODUÇÃO}

Micotoxinas são metabólitos secundários produzidos por algumas espécies de fungos filamentosos que podem ocorrer em alimentos, como resultado do crescimento fúngico (GONÇALVEZ et al., 2001; GQALENI et al., 1997 SWEENEY \& DODSON, 1998).

Os fungos mais comuns encontrados em alimentos e produtos estocados pertencem ao gênero Aspergillus ou Penicillium (GARCIA et al., 2002; NGUYEN et al., 2007). Algumas espécies de fungos podem produzir micotoxinas, ocasionando significativas perdas econômicas e sérios problemas à saúde humana e animal (HUSSEIN \& BRASEL, 2001; IARC, 2002). No entanto, o simples isolamento e a confirmação de fungos micotoxigênicos em alimentos não indicam a presença de micotoxinas (HUSSEIN \& BRASEL, 2001; GUITAKOU et al., 2006).

Mais de 20 espécies de Aspergillus produzem micotoxinas, sendo as mais comuns as da divisão flavi, que incluem três espécies: $A$. flavus, $\boldsymbol{A}$. parasiticus, A. nomius (VAAMONDE et al., 2003; SALEEMULLAH et al., 2006). As quatro aflatoxinas naturalmente produzidas são $B_{1}, B_{2}, G_{1}, G_{2}$; sendo que a $\mathrm{B}_{1}$ é usualmente encontrada em grandes concentrações, contaminando alimentos (D'MELLO \& MACDONALD, 2002; GUITAKOU et al., 2006; MOSS, 2002).

ILaboratório de Toxicologia, Instituto de Ciência e Tecnologia de Alimentos (ICTA), Universidade Federal do Rio Grande do Sul (UFRGS). Av. Bento Gonçalves, 9500, prédio 43212, Campus do Vale, Agronomia, Porto Alegre, RS, Brasil. E-mail: anacarolina.ritter@gmail.com.*Autor para correspondência. 
A aflatoxina $\mathrm{B} 1$ possui potencial hepatotóxico, carcinogênico e teratogênico tanto em homens como em animais (SWEENEY \& DOBSON,1998; MARKLINDER et al.,2005; MOSS, 2002; PILDAIN et al., 2004). Em 1993, a International Agency for Research on Câncer (IARC) (WHOIARC,1993) considerou as aflatoxinas como carcinogênicas para humanos (grupo I) (HUSSEIN \& BRASEL, 2001; IARC, 2002).

As circunstâncias que promovem a produção de aflatoxinas são geralmente mais restritas que aquelas que promovem o crescimento fúngico (GONÇALVEZ et al., 2001). Composição do substrato, temperatura, teor de água, umidade relativa do ar, atividade de água, pH e linhagem do fungo contaminante são fatores que governam a produção de aflatoxinas, sendo que a temperatura, a umidade e o tipo de substrato são os fatores mais importantes (MALLOZZI \& CORRÊA, 1998; GQALENI et al., 1996 TANIWAKI \& SILVA, 2001; MOLINA \& GIAMUZZI, 2002; GQALENI et al., 1997).

Tendo em vista os aspectos mencionados, o presente estudo teve por objetivos avaliar a capacidade produtora de aflatoxina $B_{1}$ de três cepas de Aspergillus flavus no substrato em que foram isolados (arroz) e observar o efeito de diferentes pré-inóculos (meios de cultura sintéticos) nestas cepas conhecidamente aflatoxigênicas.

\section{MATERIAL E MÉTODOS}

\section{Isolados utilizados}

Para realização deste trabalho, foram utilizados três isolados de Aspergillus flavus, produtores de aflatoxina $B$, encontrados e identificados por HOELTZ (2005) em amostras de arroz com casca. Esses isolados foram denominados A21, A43 e A46 pela fungoteca do Laboratório de Toxicologia (ICTA/ UFRGS).

\section{Delineamento experimental}

Para realização deste experimento, foi realizado um teste prévio com os três isolados em meios sintéticos (dados não publicados), em que foram testadas temperaturas de $20,25,30,35$ e $40^{\circ} \mathrm{C}$ e tempos de incubação de sete, 11, 14, 18 e 21 dias. As melhores combinações desses dias e as temperaturas encontradas $\left(25^{\circ} \mathrm{C} / 11\right.$ dias, $20^{\circ} / 14$ dias e $25^{\circ} \mathrm{C} / 18$ dias) foram aplicadas nos testes com arroz.

Meios de cultivo

Meios sintéticos: YES- Yeast Extrat Sucrose (2g extrato de levedura, $150 \mathrm{~g}$ de sacarose, $20 \mathrm{~g}$ de agar, 0.5g de sulfato de magnésio e $100 \mathrm{~mL}$ de água destilada); CYA- Czapeck Yeast Extrat (5,0g de extrato de levedura, $30 \mathrm{~g}$ de sacarose, 15,0g de agar, $10,0 \mathrm{~mL}^{-1}$ de Czapeck concentrado, $1,0 \mathrm{~g}$ de $\mathrm{H}_{2} \mathrm{HPO}_{4}$ e $100 \mathrm{~mL}$ de água destilada); Agar Sabouraud (neopeptona 10,0g, dextrose 40,0g e ágar 20,0g (MERCK, Darmastadt, Alemanha). Meio Natural: arroz parboilizado, livre de micotoxina, com umidade inicial de 12,89\%.

Análise do potencial toxigênico dos três isolados conhecidamente aflatoxigênicos

As três cepas produtoras de aflatoxina $B_{1}$ foram testadas em arroz parboilizado. A partir de cada cepa selecionada, uma suspensão de esporos foi preparada em Tween $80 \%$. Os esporos foram contados em uma Câmara de Neubauer e o volume necessário para obter-se $10^{6} \mathrm{ml}^{-1}$ esporos foi inoculado em erlenmeyers (125mL) com $15 \mathrm{~g}$ de arroz estéril a $73 \%$ de umidade (atividade de água de 0,99), em duplicata (PARK \& BULLERMAN, 1983). Estes foram tampados com algodão e incubados em estufa BOD em uma combinação de tempo e temperatura referentes à melhor produção de aflatoxina $B_{1}$ obtida a partir de experimentos em meios sintéticos (dados não publicados). Após este período, $30 \mathrm{ml}^{-1}$ de metanol a $80 \%$ foram adicionados aos erlenmeyers e as toxinas foram extraídas sob forte agitação por 5 minutos. Após a filtração, os extratos obtidos foram aplicados com capilares sobre placas de sílica gel 60G (MERCK, Darmastadt, Alemanha) e eluídos com tolueno: clorofórmio: acetato de etila: acido fórmico (35:25:25:10). Após desenvolvimento do cromatograma, as placas foram visualizadas sob luz ultravioleta de comprimento de onda longo (365nm) para detecção da fluorescência característica de aflatoxina $B_{1}$ (SMEDSGAARD, 1997; GQALENI et al., 1996; VAAMONDE et al., 2003; BELLÍ et al., 2004; ABRANSON \& CLEAR, 1996; LEONTOPOULOS et al., 2003; PARK \& BULLERMAN, 1983; GUITAKOU et al., 2006).

\section{RESULTADOS E DISCUSSÃO}

As melhores condições de temperatura e tempo de incubação encontradas para produção de aflatoxina testada com os meios sintéticos foram aplicadas nos testes com arroz $\left(25^{\circ} \mathrm{C} / 11\right.$ dias, $25^{\circ} / 18$ dias e $20^{\circ} \mathrm{C} / 14$ dias). Inicialmente, os fungos produtores foram retirados de pré-inóculos feitos em agar sabouraud (Tabela 1). De acordo com estes testes, apenas a cepa A43 mostrou-se produtora de aflatoxina $\mathrm{B}_{1}$, no tempo de 18 dias, em temperatura de $25^{\circ} \mathrm{C}$. Em virtude destes resultados não serem satisfatórios, realizou-se um novo experimento, em que as cepas 
Tabela 1 - Teste dos isolados fúngicos (A43, A46, A21) produtores de aflatoxina $\mathrm{B}_{1}$, retirados dos pré-inóculos (Czapeck Yeast Extrat (CYA), Yeast Extrat Sucrose (YES) e Sabouraud (SAB)) inoculados no arroz.

\begin{tabular}{lcccccccc}
\hline & A43 & & A46 & & A21 \\
\hline Pré-inoculo & SAB & CYA & YES & SAB & CYA & YES & SAB & CYA \\
$25^{\circ} \mathrm{C} / 11$ dias & - & - & - & - & - & - & - & - \\
$20^{\circ} \mathrm{C} / 14$ dias & - & - & + & - & - & + & - & - \\
$25^{\circ} \mathrm{C} / 18$ dias & + & + & + & - & + & + & - & - \\
\hline
\end{tabular}

(-) Não houve produção de aflatoxina $\mathrm{B}_{1}$.

(+) Houve produção de aflatoxina $\mathrm{B}_{1}$.

produtoras foram inoculadas nos meios CYA e YES por sete dias (pré-inóculo). Neste teste, a contagem de esporos (provenientes dos pré-inóculos em CYA e YES) foi realizada para uma concentração de $10^{6} \mathrm{l} \mathrm{ml}^{-1} \mathrm{e}$, em seguida, as cepas foram inoculadas nos erlenmeyers contendo as amostras de arroz (15g) a serem analisadas. A partir desse teste, verificou-se que todas as cepas retiradas do pré-inóculo em meio YES e inoculadas no arroz, em temperatura de $25^{\circ} \mathrm{C} / 18$ dias e $20^{\circ} \mathrm{C} / 14$ dias, produziram aflatoxina $\mathrm{B}_{1}$ (Tabela 1 ).

Os isolados A43 e A21 retirados do préinóculo CYA se mostraram produtores, porém, em apenas uma condição de cultivo $\left(25^{\circ} \mathrm{C}\right.$ em 18 dias). $\mathrm{O}$ isolado A46 mostrou-se deficiente em relação à produção de aflatoxina quando inoculado no meio CYA. Este dado foi similar ao encontrado por PARK \& BULLERMAN (1983), que concluíram que a produção de $\mathrm{AFB}_{1}$ depende acima de tudo da linhagem isolado fúngico.após estudarem inóculo de Aspergillus flavus e parasiticus em arroz.

O meio YES utilizado como pré-inoculo apresentou maior desempenho, quando comparado com meio CYA, uma vez que houve produção de aflatoxina $\mathrm{B}_{1}$ pelos três isolados testados (Tabela 1), além de mais de uma condição $\left(25^{\circ} / 18\right.$ dias e $20^{\circ} \mathrm{C} / 14$ dias). LEONTOPOULOS et al. (2003) concluiram que YES Agar é um ótimo meio para biossíntese de aflatoxina B1 e que, além de ser de fácil preparação, é relativamente barato.

Vários substratos já foram testados para verificar o potencial toxigênico fúngico. Um exemplo foi o estudo realizado por KOKKONEN et al. (2004), que, após analisarem vários substratos para examinar a capacidadedo fungo em produzir micotoxinas, verificaram que linhagens de Penicillium produziram várias micotoxinas diferentes, dependendo do meio e da linhagem. A partir deste dado, os autores concluíram que existe uma grande necessidade de se utilizar mais de um meio de cultura para verificar e identificar os metabólitos fúngicos.
O arroz se mostrou um meio utilizável para testes de potencial toxigênico devido ao fato de que todos os isolados conhecidamente aflatoxigênicos utilizados neste experimento produziram aflatoxina. PARK \& BULLERMAN (1983) inocularam esporos de duas espécies de Aspergillus flavus e parasiticus, em arroz e queijo, e analisaram o efeito da variação de temperatura nestes substratos $\left(25^{\circ} \mathrm{C}, 18^{\circ} \mathrm{C}, 5-25^{\circ} \mathrm{C}, 15^{\circ} \mathrm{C}\right.$ e $5^{\circ} \mathrm{C}$ ). Tais autores concluíram que o queijo não é um bom substrato para produção de aflatoxinas, ao contrário do arroz.

De acordo com RAYBAUDI et al. (2000), em um estudo de potencial toxigênico, realizado com isolado de Aspergillus flavus e parasiticus, cerca de $37 \%$ dos isolados apresentaram produção de aflatoxinas em arroz, enquanto que somente cerca de 4\% dos testados produziram aflatoxinas em ágar coco. Já BRESLER et al. (1995) inocularam espécies de Aspergillus em arroz e constataram que quatro de 34 isolados de A. flavus foram produtores de aflatoxinas e seis de um total de 12 A. parasiticus se mostraram aflatoxigênicos neste meio. Tais autores concluíram que fungos toxigênicos podem ser facilmente encontrados, mas a produção de micotoxinas pode aparecer somente durante uma prolongada estocagem de produtos contaminados.

As temperaturas de $20^{\circ} \mathrm{C} \mathrm{e} 25^{\circ} \mathrm{C}$ mostraramse boas para produção de aflatoxina $\mathrm{B}_{1}$ nas amostras de arroz analisadas neste trabalho. Para OSWEILER (1998), a faixa de temperatura para formação de aflatoxinas é de $25^{\circ} \mathrm{C}$ a $32^{\circ} \mathrm{C}$, contudo, a temperatura de $13^{\circ} \mathrm{C}$ por dois ou mais dias ainda permite a formação de aflatoxina. SAMAPUNDO et al. (2007), ao inocularem A.flavus em grãos de pipoca, verificaram que os isolados testados tiveram ótimo crescimento a $30^{\circ} \mathrm{C}$.

PARK \& BULLERMAN (1983) demonstraram que a produção de aflatoxinas pode ser afetada por flutuação de temperatura. A exposição de A. parasiticus a temperaturas altas (entre 40 e $50^{\circ} \mathrm{C}$ ), por um curto período de tempo, reduz o crescimento e a produção de aflatoxinas. 
No que se refere ao crescimento fúngico no arroz analisado, pode-se perceber que a partir do $2^{\circ}$ dia de incubação em qualquer uma das temperaturas testadas já houve um crescimento superficial destes bolores. Estes dados novamente são similares com os obtidos por PARK \& BULLERMAN (1983), que também notaram um crescimento de Aspergillus flavus a partir do segundo dia de incubação, na temperatura de $25^{\circ} \mathrm{C}$. GQALENI et al. (1997) demonstraram em seu estudo que as espécies de Aspergillus flavus estudadas tiveram uma ótima temperatura para colonização do substrato na faixa de 25 a $30^{\circ} \mathrm{C}$. Segundo TANIWAKI \& SILVA (2001), o A. flavus apresenta temperatura mínima de crescimento por volta de $12^{\circ} \mathrm{C}$, máxima próxima de $48^{\circ} \mathrm{C}$ e ótima entre 30 e $42^{\circ} \mathrm{C}$.

No $11^{\circ}$ dia, o crescimento atingiu seu máximo. A esporulação dos isolados foi notada a partir do 7ํ dia. Para LEONTOPOULOS et al. (2003), o máximo crescimento do micélio de um isolado de Aspergillus flavus foi ao $6^{\circ}$ dia após a inoculação. Depois deste período, uma moderada desaceleração do crescimento do micélio foi observada. Tais resultados indicam também a importância que o meio YES exerce sobre os isolados fúngicos em relação à esporulação fúngica. PARK \& BULLERMAN (1983) constataram que o crescimento de Aspergillus flavus e A. parasiticus em ágar BDA não foi bom, pois não houve esporulação suficiente. A partir deste resultado, antes de inocularem os esporos desses isolados em arroz, esses pesquisadores fizeram o crescimento destes isolados em meio YES, sendo que a esporulação foi notoriamente boa para contagem de esporos e inoculação no meio natural.

BU’LOCK (1965) afirma que o mecanismo de esporulação tem uma conexão com metabólitos secundários. Para PARK \& BULLERMAN (1983), o tempo requerido para iniciar o crescimento e a esporulação de Aspergillus flavus e Aspergillus parasiticus em amostras de arroz foi afetado pela temperatura, pelo substrato e pela linhagem do fungo. $\mathrm{O}$ início do crescimento ocorreu mais rápido a $25^{\circ} \mathrm{C}$, seguido de $18^{\circ} \mathrm{C}$ da temperatura cíclica $\left(5-25^{\circ} \mathrm{C}\right)$ e $15^{\circ} \mathrm{C}$. Esses autores concluíam que a temperatura foi um fator determinante para o crescimento e a esporulação fúngica.

A atividade de água de 0,99 do arroz mostrou-se boa para produção de aflatoxinas, conferindo com os resultados encontrados por GQALENI et al. (1997), em que a atividade de água do substrato (CYA e YES) de 0,99 foi considerada ótima para produção de aflatoxinas. No mesmo, estudo a produção de aflatoxina foi afetada por diferentes substratos, tempos de incubação e presença de outras micotoxinas produzidas por A. flavus. Samapundo et al (2007) observaram que isolados de Aspergillus, quando inoculados em grãos de pipoca, não cresceram em atividade de água de 0.801 . Em geral, as aflatoxinas são produzidas a valores de aw de 0,95 a 0,99 com um valor mínimo de 0,82 para A.flavus (ICMSF,1996; NIELSEN, et al., 2004).

\section{CONCLUSÃO}

Os resultados deste estudo sugerem que os meios sintéticos CYA e, principalmente, YES servem como um execelentes substratos (pré-inóculo) para produção de aflatoxinas, pois demonstram que são capazes de ativar a produção das mesmas. O arroz, quando incubado em um período de 14 ou 18 dias em temperaturas de 20 e $25^{\circ} \mathrm{C}$, também mostrou-se um bom substrato natural para detecção de aflatoxina B1. Estes dados revelam também que temperatura e umidade devem ser evitadas nos silos de armazenamento de arroz. A quantificação de aflatoxina B1 e os fatores que levam os meios CYAe YES utilizados como pré-inóculos a promoverem uma melhor produção de aflatoxinas refletem a necessidade de novos estudos.

\section{REFERÊNCIAS}

ABRANSON, D.; CLEAR, R.M. A convenient method for assessing mycotoxin production in cultures of Aspergilli and Penicillia. Journal of Food Protection, Boston, v.59, p.142144,1996 .

BELLÍ, N. et al. Influence of water activity and temperature on growth of isolates of Aspergillus section Nigri obtained from grapes. International Journal of Food Microbiology, Amsterdan, v.96, p.19-27, 2004.

BRESLER, G. et al. Mycotoxin-production potential of fungi isolated from amaranth seeds in Argentina. International Journal of Food Microbiology, Amsterdan, v.25, p. 101108, 1995.

BU'LOCK, J.D. Aspects of secondary metabolism in fungi. Slovakia: Academic, 1965. 320p.

D’MELLO, J.P.F.; MACDONALD, A.M.C. Mycotoxins. Animal Feed Science Technology, London, v.69, p.155166, 2002.

GARCIA, M.J.M. et al. Sucessão de espécies de fungos em milho armazenado em sistema aerado. Revista Brasileira de Armazenamento. Viçosa, v.27, n.2, p.14-22, 2002.

GONÇALVEZ, E. et al. Análises de micotoxinas no instituto biológico de 1989 a 1999. Biológico, São Paulo, v.63, p.1519, 2001.

GUITAKOU, S. et al. Study of aflatoxin B1 and ochratoxin A production by natural microflora and Aspergillus parasiticus in 
black and green olives of Greek origin. Food Microbiology, London, v.23, p.612-621, 2006.

GQALENI, N. et al. Co-production of aflatoxin and cyclopiazonic acid in isolates of Aspergillus flavus. Food Additives and Contaminants, Sidney, v.13, p.677-685, 1996.

GQALENI, N. et al. Effects of temperature, water activity, and incubation time on production of aflatoxins and cyclopiazonic acid by an isolate of Aspergillus flavus in surface Agar culture. Applied and Environmental Microbiology, Vancouver, v.63, p.1048-1053, 1997.

HUSSEIN, H.S.; BRASEL, J.M. Toxicity, metabolism, and impact of mycotoxin on humans and animals. Toxicology, Amsterdam, v.167, p.101-134, 2001.

HOELTZ, M. Estudo da influência de manejos póscolheita na incidência de fungos e micotoxinas no arroz (Oryza sativa L.). 2005. 77f. Dissertação (Mestrado em Microbiologia dos Alimentos) - Programa de Pós-graduação em Microbiologia Agrícola e do Ambiente, Faculdade de Agronomia, Universidade Federal do Rio Grande do Sul, Porto Alegre.

IARC-International Agency for Research on Câncer. Some naturally occurring substance: food items and contituents, heterocyclic aromatic aminesand mycotoxins. Lyon: OMS, 2002.

ICMSF- International Commission on Microbiological Specifications for Foods. Microorganisms in Foods. London: Academic, 1996. p.347-381.

KOKKONEN, M. et al. The effect of substrate on mycotoxin production of selected Penicilium strains. International Journal of Food Microbiology, Amsterdan, v.56, p.67-74, 2004.

LEONTOPOULOS, D. et al. Black olives as substrate for Aspergillus parasiticus growth and aflatoxin B1 production. Food Microbiology, London, v. 20, p.119-126, 2003.

MALLOZZI,M.; CORREA, B. Fungos toxigênicos e micotoxinas. Boletim do Instituto Técnico de Biologia , São Paulo, v.3, p.5-26,1998.

MARKLINDER, I. et al. Consumer's ability to descriminate aflatoxin-contaminate Brasil nuts. Food Additives and Contaminants, Sidney, v.22, p.54-64, 2005.

MOLINA, M.; GIAMUZZI, L. Modelling of aflatoxin production by Aspergillus parasiticus in a solid medium at different temperatures, $\mathrm{pH}$ and propionic acid concentrations. Food Research International, London, v.35, p.585-594, 2002.

MOSS, M. Mycotoxin review- Aspergillus e Penicillium. Mycologist, Cambridge, v16, n.3, p.116-119, 2002.
NGUYEN, M.T. et al. Occurrence of aflatoxin B1, citrinin and ochratoxin A in rice in five provinces of the central region of Vietnam. Food Chemistry, Japan, v.105, 42-47, 2007.

NIELSEN, K.F. et al. Mould growth on building materials under low water activities. Influence of humidity and temperature on fungal groth and secondary metabolism. International Biodeterioration \& Biodegradation, London, v.54, p.325336, 2004.

OSWEILER, G.D. Toxicologia veterinaria. São Paulo: Arte Médicas, 1998. 526p.

PARK ,K.Y.; BULLERMAN, L.B. Effect of cycling temperatures on aflatoxin production by Aspergillus parasiticus and Aspergillus flavus in rice and cheddar cheese. Journal of Food Science, Chicago, v.48, p.889-896, 1983.

PILDAIN, M.B. et al. Analysis of population structure of Aspergillus flavus from peanut based on vegetative compatibility, geographic origin, mycotoxin and sclerotia production. International Journal of Food Microbiology, Amsterdan, v.93, p.31-40, 2004.

RAYBAUDI, R. et al. Incidence of aflatoxin in corn as related to levels of Aspergillus flavus/parasiticus and moisture content. In: INTERNATIONAL IUPC SYMPOSIUM ON MYCOTOXIN AND PHYCOTOXINS, 10., 2000 São Paulo. Anais de Evento no Pais... Guarujá, SP. Instituto Adolfo Lutz, 2000. p.135.

SAMAPUNDO,S. et al. Modelling of the individual and combined effects of water activity and temperature on the radial growth of Aspergillus flavus and A.parasiticus on corn. Food Microbiology, London v.24,p.517-529,2007.

SALEEMULLAH, A.I. et al. Aflatoxin contents of stored and artificially inoculated cereals and nuts. Food Chemistry, Japan, v.98, p.699-703, 2006.

SMEDSGAARD, J. Micro-scale extraction procedure for standardized screening of fungal metabolite production in cultures. Journal of Chromatografy A, Amsterdan, v.706, p.264-270, 1997.

SWEENEY, J.; DOBSON, A.D.W. Mycotoxin production by Aspergillus, Fusarium and Penicillium species. International Journal of Food Microbiology, Amsterdan, v.43, p.141-158, 1998.

TANIWAKI,M.H.: SILVA, N. Fungos em alimentos: ocorrência e deteç̧ão. Campinas: Núcleo de Microbiologia do ITAL, 2001. 82p.

VAAMONDE, G. et al. Variability of aflatoxin and cyclopiazonic acid production by Aspergillus section flavi from different substrates in Argentina. International Journal of Food Microbiology, Amsterdan, v.88, p.79-84, 2003. 